\title{
Curve Fitting Analysis of Internet Traffic Sharing Management in Computer Network under Cyber Crime
}

\author{
Diwakar Shukla ${ }^{[1]}$, Kapil Verma ${ }^{[2]}$, Shree Bhagwat ${ }^{[3]}$ and Sharad Gangele ${ }^{[4]}$ \\ ${ }^{[1]}$ Deptt. of Mathematics and Statistics, Sagar University, Sagar M.P., India. \\ ${ }^{[2]}$ Deptt. of Computer Science, M. P. Bhoj (Open) University, Bhopal and \\ B.T. Institute of Research and Technology, Seronja, Sagar, M.P., India \\ ${ }^{[3]}$ Faculty of Management Studies, Dr, H.S. Gour University, Sagar, M.P. India \\ ${ }^{[4]}$ Deptt. of Mathematics, M.B. Khalsa College, Indore, M.P., India
}

\begin{abstract}
Cyber crime is growing fast day-by-day through the spreading of Internet around the world. Many under-developed countries are using dial-up-setup network where a call is connected only after a little extra effort. Some identified cyber crimes are writing abusive letters, giving threats to other, sending unwanted mails, hacking secret data, phishing attack on websites etc. The Internet traffic growth has some positive correlation with the cyber crime as justified by the Markov Chain Model based analysis of authors to examine the interrelationship between traffic sharing and blocking probability. This analysis has been extended for two-call basis also and model based relations are derived. These relations are complicated in terms of mathematical structure. This paper presents least square based curve analysis for Markov Chain model based relationship between traffic sharing and network blocking. The earlier suggested complicated relationship has been simplified in the form of straight line showing a good fitting. The Coefficient of determination has been computed showing the high value towards unity. It proves that simplified linear relationships perform well as a thumb rule for expressing the complex relationship between traffic sharing and network blocking probability. .
\end{abstract}

\section{Keywords}

User behavior, Transition Probability Matrix (TPM), Markov Chain Model (MCM), Coefficient of Determination (COD), Confidence Interval.

\section{INTRODUCTION}

Naldi [5] has suggested Markov Chain model for the analysis of Internet traffic sharing with the blocking probability of computer network. This approach was under assumption that there is only single call attempt allowed. Shukla et al. [32] have extended the problem to the case of call basis. Shukla, Tiwari and Thakur [25] has extend the approach of Naldi [5] of to the case of cyber crime presence. Cyber criminals get opportunities to perform harmful activities through computer network. When the call is connected few popular cyber crimes are hacking, phishing attack, unwanted mails, threatening mails etc. after the call connection using dial-up-setup, there are two possibilities. (i) either the user performs cyber crime or does not. Shukla, Tiwari and Thakur [32] established a relationship between traffic sharing by cyber criminals and blocking probabilities of computer network. This relationship is non linear contains many model parameters as input sources. This paper presents an approach to simplify the complex relationship into a linear form under the setup of cyber crime and two call basis attempts. The Markov chain based approach suggested by Naldi [5] is the main focus which has been extended in the environment of curve fitting approach. Shukla and Thakur [12] have some useful contribution on cyber crime analysis using a Markov Chain Model.

\section{A REVIEW}

The network system as a random process has been assumed by many researchers for the purpose of statistical modelling whose detailed description is in Medhi [1], [2]. Chen and Mark [3] discussed the fast packet switch shared concentration and output queueing for a busy channel. Hambali and Ramani [4] evaluated multicast switch with a variety of traffic patterns. Newby and Dagg [6] have a useful contribution on the optical inspection and maintenance for stochastically deteriorating system. Dorea et al. [8] used Markov chain for the modelling of a system and derived some useful approximations. Yeian and Lygeres [10] presented a work on stabilization of class of stochastic different equations with Markovian switching. Shukla et al. [11] advocated for model based study for space division switches in computer network. Francini and Chiussi [7] discussed some interesting features for QoS guarantees to the unicast and multicast flow in multistage packet switch. On the reliability analysis of network a useful contribution is by Shukla et al. [13] whereas Paxson [9] introduced some of their critical experiences while measuring the internet traffic. Shukla et al. [14], [15], [16], [17], [18], [19] and [20] presented different dimensions of Internet traffic sharing in the light of share loss analysis. Shukla et al. [21], [22], [23], [24], [25] and [26] have given some Markov Chain model applications in view to disconnectivity factor, multi marketing and crime based analysis. Shukla and Thakur [27] presented Index based internet traffic analysis of users by a Markov chain model . Shukla et al. [28], [29], [30], [31] and [32] discussed cyber crime analysis for multidimensional effect in computer network and internet traffic sharing. Shukla et al. [33], [34], [35], [36], [37], [38], [39] and [40] discussed the elasticity property and its impact on parameters of internet traffic sharing in presence blocking probability of computer network specially when two operators are in business competitions with each other in a market. Shukla et al. [41] presented analysis of user web browsing using Markov chain model for iso-browser share probability. Shukla et al. [43] studied least square curve fitting for Iso-failure in web browsing using Markov chain model. Shukla et al. [44] studied least square curve fitting in internet access traffic sharing in two operator environment. Shukla et al. [45] discussed least square curve fitting applications under rest state environment in internet traffic sharing in computer network. Shukla et al. [46] presented curve fitting approximation in internet traffic distribution in computer network in two market environments. Shukla et al. [47] studied cyber crime based curve fitting analysis in internet traffic sharing in computer network. 


\section{ASSUMPTIONS FOR SYSTEM AND}

USER BEHAVIOUR [As per Shukla, Tiwari and Thakur (2010 d)]

(a) The user chooses, operator $\mathrm{O}_{1}$ with probability $\mathrm{p}$ or operator $\mathrm{O}_{2}$ with probability $(1-\mathrm{p})$.

(b) When first attempt of connectivity fails he attempts one more to the same operator, and thereafter, switches to the next where two more consecutive attempts may appear. This we say "two-call-basis" attempts for call connectivity.

(c) User has two choices after each failed attempt;

a. he can either abandon with probability $\mathrm{p}_{\mathrm{A}}$ or

b. switch to the other operator for a new attempt.

(d) The blocking probability that a call attempt fails through the operator $\mathrm{O}_{1}$ is $\mathrm{L}_{1}$ and through $\mathrm{O}_{2}$ is $\mathrm{L}_{2}$.

(e) If the call for $\mathrm{O}_{1}$ is blocked at $\mathrm{k}^{\text {th }}$ attempt $(\mathrm{k}>0)$ then in $(\mathrm{k}+2)^{\text {th }}$ user shifts to $\mathrm{O}_{2}$.

(f) Whenever call connects through either of $\mathrm{O}_{1}$ or $\mathrm{O}_{2}$ we say system reaches to the state of success after $n$ attempts.

(g) User can terminate the connectivity attempt process which is marked as abandon state $A$ with probability $\mathrm{p}_{\mathrm{A}}$ (either $\mathrm{O}_{1}$ or from $\mathrm{O}_{2}$ ).

(h) A successful call connection has a marketing package related to cyber-crime, denoted as $\mathrm{C}$, with attraction probability $\left(1-c_{1}\right)$ and detention probability $\left(1-c_{2}\right)$.

(i) After connectivity, user has two choices either to do or cyber-crime or to do usual web surfing through Internet (with probability $\mathrm{c}_{1}$ ). This choice is treated as an attempt related to web connectivity.

(j) Attempt means call-connecting attempt or surfing attempt.

(k) User may come-back to usual surfing whenever willing (with probability $c_{2}$ ) or may continue with cyber crime depending on attraction of marketing plan.

(1) From crime, user can neither abandon nor disconnect.

(m) From state of normal surfing, user can not abandon.

(n) State non-crime and abandon are absorbing state.

\section{MARKOV CHAIN MODEL [As per Shukla,} Tiwari and Thakur (2010 d)]

Using above hypotheses about user's behavior it can be modeled by a five-state discrete-time Markov chain $\left\{X^{(n)}, n \geq\right.$ 0 ) such that $X^{(n)}$ stands for the state of random variable $X$ at $\mathrm{n}^{\text {th }}$ attempt (call or surfing) made by a user over the state space $\left\{\mathrm{O}_{1}, \mathrm{O}_{2}, \mathrm{NC}, \mathrm{A}, \mathrm{C}\right\}$ where,

State $\mathrm{O}_{1}$ : User attempting to connect a call through the first operator $\mathrm{O}_{1}$.

State $\mathrm{O}_{2}$ : Corresponding to a call through second operator $\mathrm{O}_{2}$.

State NC: Success (in connectivity) but no cyber-crime.

State A: User leaving (abandon) the attempt process.

State C: Connectivity gained and cyber-crime.

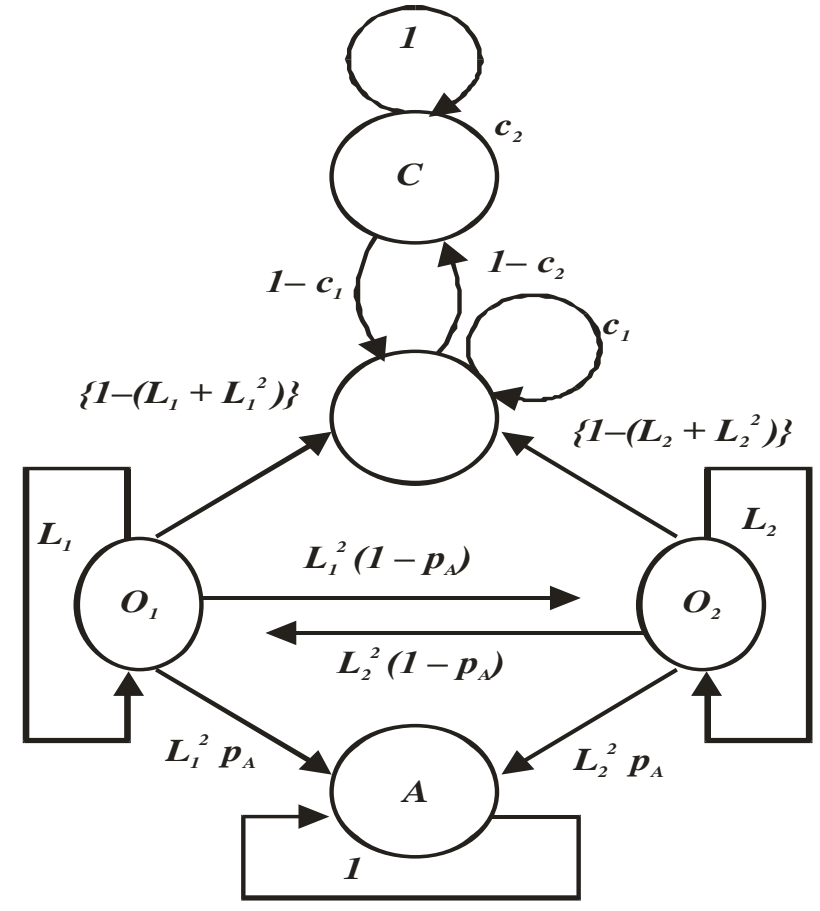

Fig.:- 1 Transition Diagram of Model [As per Shukla,

Tiwari and Thakur (2010 d)]

The connectivity attempts between two operators are on twocall basis, which means if the call for $\mathrm{O}_{1}$ is blocked in $\mathrm{k}^{\text {(th) }}$ attempt $(\mathrm{k}>0)$, then in $(\mathrm{k}+2)^{\mathrm{th}}$ user shifts to $\mathrm{O}_{2}$. When call connects either through $\mathrm{O}_{1}$ or $\mathrm{O}_{2}$ the system reaches to the state of success (NC) and does not perform cyber crime in next attempt with probability $c_{1}$. From state $\mathrm{C}$, user cannot move to states $\mathrm{O}_{1}, \mathrm{O}_{2}$ or A without passing through NC. The $\mathrm{A}$ is absorbing state.

\section{TRANSITION MECHANISM IN} MODEL AND PROBABILITIES [As per Shukla, Tiwari and Thakur (2010 d)]

Rule 1: User attempts to $\mathrm{O}_{1}$ with initial probability $\mathrm{p}$ (based on QoS the $\mathrm{O}_{1}$ provides).

Rule 2: If fails, then reattempts to $\mathrm{O}_{1}$.

Rule 3: User may succeed to $O_{1}$ in either of one attempt or next. Since the blocking probability for $\mathrm{O}_{1}$ in one attempt is $\mathrm{L}_{1}$, therefore, blocking probability for $\mathrm{O}_{1}$ in the next attempt is:

$=\mathrm{P}\left[\mathrm{O}_{1}\right.$ blocked in an attempt $] . \mathrm{P}\left[\mathrm{O}_{1}\right.$ blocked in next attempt / previous attempt to $\mathrm{O}_{1}$ was blocked $]=\left(\mathrm{L}_{1} \cdot \mathrm{L}_{1}\right)$ $=\mathrm{L}_{1}^{2}$

The total blocking probability is $\left(\mathrm{L}_{1}+\mathrm{L}_{1}^{2}\right)$ inclusive of both attempts. The success probability for $\mathrm{O}_{1}$ is $\left[1-\left(\mathrm{L}_{1}\right.\right.$ $\left.\left.+\mathrm{L}_{1}^{2}\right)\right]$ Similar for $\mathrm{O}_{2}=\left[1-\left(\mathrm{L}_{2}+\mathrm{L}_{2}^{2}\right)\right]$

Rule 4: User shifts to $\mathrm{O}_{2}$ if blocks in both attempts to $\mathrm{O}_{1}$ and does not abandon. The transition probability is:

$=\mathrm{P}\left[\mathrm{O}_{1}\right.$ blocked in an attempt $] . \mathrm{P}\left[\mathrm{O}_{1}\right.$ blocked in next attempt/previous attempt to $\mathrm{O}_{1}$ was blocked]. $\mathrm{P}$ [does not abandon attempting process $]=\mathrm{L}_{1}^{2}\left(1-\mathrm{p}_{\mathrm{A}}\right)$ Similar for $\mathrm{O}_{2}=\mathrm{L}_{2}^{2}\left(1-\mathrm{p}_{\mathrm{A}}\right)$. 
Rule 5: User either abandons the system atleast after two attempts to an operator, which is a compulsive with this model. This leads to probability that user abandons process after two attempts over $\mathrm{O}_{1}$ is:

$=\mathrm{P}\left[\mathrm{O}_{1}\right.$ blocked in an attempt $] . \mathrm{P}\left[\mathrm{O}_{1}\right.$ blocked in next attempt/previous attempt to $\mathrm{O}_{1}$ was blocked]. $\mathrm{P}$ [abandon the attempting process] $=\mathrm{L}_{1}^{2} \mathrm{p}_{\mathrm{A}}$ Similar happens for $\mathrm{O}_{2}=\mathrm{L}_{2}^{2} \mathrm{p}_{\mathrm{A}}$

Rule 6: for, $0 \leq \mathrm{c}_{1} \leq 1$ and $0 \leq \mathrm{c}_{2} \leq 1$ we have

$$
\begin{aligned}
& \left.P\left[X^{(n)}=C / X^{(n-1)}=N C\right]=1-c_{1}\right] \\
& \left.P\left[X^{(n)}=N C / X^{(n-1)}=N C\right]=c_{1}\right] \\
& \left.P\left[X^{(n)}=N C / X^{(n-1)}=C\right]=c_{2}\right] \\
& \left.P\left[X^{(n)}=C / X^{(n-1)}=C\right]=1-c_{2}\right]
\end{aligned}
$$

\section{TRANSITION PROBABILITY}

\section{BETWEEN STATES}

$$
\left\{X^{(n)}, n=0,1,2,3, \ldots \ldots \ldots . . .\right\} \text { where } X^{(n)} \text {, denotes the }
$$

state of user at $\mathrm{n}^{\text {th }}$ attempt to connect (or succeed) a call while transitioning among five states $\mathrm{O}_{1}, \mathrm{O}_{2}, \mathrm{NC}, \mathrm{C}$ and $\mathrm{A}$, at $\mathrm{n}=0$, we have

$$
\begin{aligned}
& P\left[X^{(0)}=O_{1}\right]=p \\
& P\left[X^{(0)}=O_{2}\right]=(1-p) \\
& P\left[X^{(0)}=N C\right]=\mathrm{O} \\
& P\left[X^{(0)}=C\right]=\mathrm{O} \\
& P\left[X^{(0)}=A\right]=\mathrm{O}
\end{aligned}
$$

Now, the transition probability matrix is

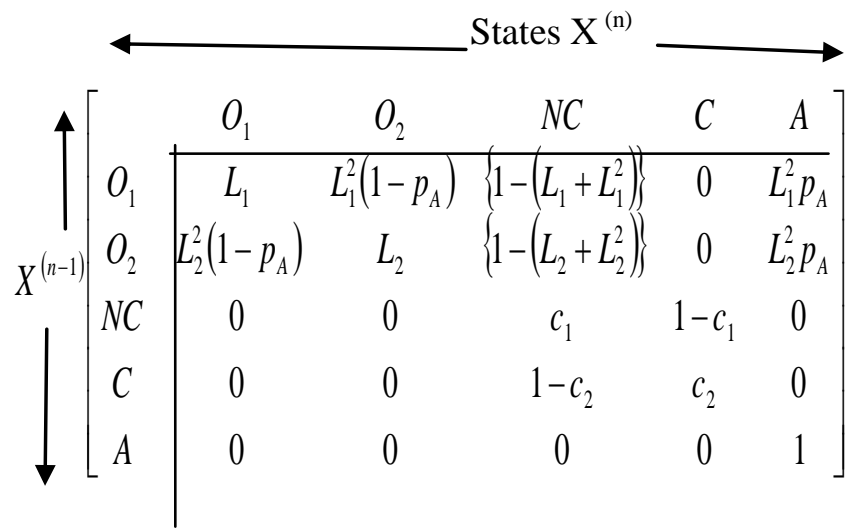

Table: 6.1 [Transition Probability Matrix] [As per Shukla, Tiwari and Thakur (2010 d)]

\section{CURVE FITTING ANALYSIS OVER LARGE NUMBER OF ATTEMPT}

$$
\begin{aligned}
& {\left[\bar{P}_{1}\right]_{C C}=\left[\left\{1-\left(L_{2}+L_{2}^{2}\right)\right\}\left(1-c_{1}\right)\left\{\begin{array}{l}
\frac{\left[\left(L_{1} p+p\right)\right]}{1-\left[L_{1}^{(3)} L_{2}^{(3)}\left(1-p_{A}\right)^{(2)}\right]}+ \\
\frac{\left(L_{1}(1-P)+(1-P)\right)\left[L_{2}^{(3)}\left(1-p_{A}\right)\right]}{1-\left[L_{1}^{(3)} L_{2}^{(3)}\left(1-p_{A}\right)^{(2)}\right]}
\end{array}\right\}\right]} \\
& {\left[\bar{P}_{2}\right]_{C C}=\left[\left[\left\{1-\left(L_{2}+L_{2}^{2}\right)\right\}\left(1-c_{1}\right)\right]\left\{\begin{array}{l}
\frac{\left(L_{2}(1-p)+(1-p)\right)}{1-\left[L_{1}^{(3)} L_{2}^{(3)}\left(1-p_{A}\right)^{(2)}\right]} \\
\left.+\frac{\left[\left(L_{2} P+p\right) L_{1}^{(3)}\left(1-p_{A}\right)\right]}{1-\left[L_{1}^{(3)} L_{2}^{(3)}\left(1-p_{A}\right)^{(2)}\right]}\right]
\end{array}\right\}\right.}
\end{aligned}
$$

$$
\bar{P}_{1 A C C}=\left[\frac{\left(1-C_{1}\right) L_{1} \cdot p\left\{1-\left(L_{1}+L_{1}^{2}\right)\right\}}{1-L_{1}^{3} L_{2}^{3}\left(1-p_{A}\right)^{2}}\right]
$$

\section{LEAST SQUARE CURVE FITTING}

We suggest a linear relationship where $\mathrm{a}, \mathrm{b}$ are constants

$$
\overline{P_{1}}=\hat{a}+\hat{b} \cdot L_{1}
$$

Let $\left(\left(\bar{P}_{1 i}, L_{1 i}\right) i=1,2,3 \ldots . n\right.$ be $\mathrm{n}$ observations generated from equation (7.1) keeping values fixed for $p, p_{A}$ and $L_{2}$. Suppose $n=9$ and blocking probabilities for $L_{1}$ are $(0.1,0.2$, $0.3,0.4,0.5,0.6,0.7,0.8,0.9)$ then using $(8.1)$, the generated data of $\bar{P}_{1}$ is in table (1,2 and 3). The $\hat{P}_{1}$ is obtained using line equation (9.4) with $\hat{a}, \hat{b}$.

\section{FITTING THE STRAIGHT LINE}

We suggest an approximate the relationship between parameter $\mathrm{P}_{1}$ and $\mathrm{L}_{1}$ through a straight line $\hat{P}_{1}=a+b \cdot L_{1}$. The normal equations are 


$$
\left.\begin{array}{l}
\sum_{i=1}^{n} P_{1 i}=n . a+b \sum_{i=1}^{n} L_{1 i} \\
\sum P_{1 i} . L_{1 i}=a \sum_{i=1}^{n} L_{1 i}+b \sum_{i=1}^{n} L_{1 i}{ }^{2}
\end{array}\right\}
$$

By solving the above equation the least square estimate are a and $\mathrm{b}$ are (denoted as $\hat{a}, \hat{b}$ ):

$\hat{a}=\left\{\frac{1}{n} \sum_{i=1}^{n} P_{1 i}-\hat{b} \sum_{i=1}^{n} L_{1 i}\right\}$

$$
\hat{b}=\left\{\frac{n \sum_{i=1}^{n} P_{1 i} L_{1 i}-\left(\sum_{i=1}^{n} P_{1 i}\right)\left(\sum L_{1 i}\right)}{n \sum_{i=1}^{n} L_{1 i}{ }^{2}-\left(\sum_{i=1}^{n} L_{1 i}\right)^{2}}\right\}
$$

Where $\mathrm{n}$ is the number of observations in sample (n) and the resultant straight line is

$$
\hat{P}_{1}=\left\{\hat{a}+\hat{b} L_{1}\right\}
$$

The coefficient of determination (COD) is defined as

$$
\mathrm{COD}=\left\{\frac{\sum\left(\hat{P}_{1 i}-\overline{P_{1}}\right)^{2}}{\sum\left(P_{1 i}-\overline{P_{1}}\right)^{2}}\right\}
$$

Where $\overline{P_{1}}=\frac{1}{n} \sum P_{1 i}$ is mean of original data of $\mathrm{P}_{1}$ obtained through Markov chain model. The term $\hat{P}_{1}=\hat{a}+\hat{b} \cdot L_{1}$ is the estimated value give observation $\mathrm{L}_{1}$ The COD lies between 0 to 1 . If the line is good fit then it is

\begin{tabular}{|c|c|c|c|c|c|c|c|c|c|}
\hline \multicolumn{10}{|c|}{ Fixed parameter $\mathrm{p}=0.4, \mathrm{~L}_{2}=0.3, \mathrm{p}_{\mathrm{A}}=02, \mathrm{C}_{1}=0.3$} \\
\hline $\mathrm{L}_{1}$ & 0.1 & 0.2 & 0.3 & 0.4 & 0.5 & 0.6 & 0.7 & 0.8 & 0.9 \\
\hline$\overline{\mathrm{P}_{1}}$ & 0.1498 & 0.1358 & 0.1212 & 0.1061 & 0.0903 & 0.0738 & 0.0566 & 0.0386 & 0.0197 \\
\hline$\hat{P}_{1}$ & 0.1529 & 0.1366 & 0.1204 & 0.1042 & 0.0888 & 0.0717 & 0.0555 & 0.0393 & 0.0231 \\
\hline \multicolumn{10}{|c|}{$\mathrm{COD}=\mathbf{0 . 9 9 7 9 7 5}$} \\
\hline
\end{tabular}
near to 1 . We generate pair of value $\left(\mathrm{L}_{1}, \mathrm{P}_{1}\right)$ from express tables $(1,2$ and 3$)$ by providing few fixed input parameters.

Table 1

$$
\hat{a}=0.1690 ; \quad \hat{b}=-0.1622 ; \hat{P}_{1}=a+b . L_{1} ; \quad \hat{P}_{1}=0.1690-0.1622 .\left(L_{1}\right)
$$

Table 2

\begin{tabular}{|c|c|c|c|c|c|c|c|c|c|}
\hline \multicolumn{10}{|c|}{ Fixed parameter $\mathrm{p}=0.6, \mathrm{~L}_{2}=0.5, \mathrm{p}_{\mathrm{A}}=02, \mathrm{C}_{1}=0.5$} \\
\hline $\mathrm{L}_{1}$ & 0.1 & 0.2 & 0.3 & 0.4 & 0.5 & 0.6 & 0.7 & 0.8 & 0.9 \\
\hline $\mathrm{P}_{1}$ & 0.3533 & 0.3248 & 0.2942 & 0.2615 & 0.2262 & 0.1881 & 0.1469 & 0.1022 & 0.0534 \\
\hline$\hat{P}_{1}$ & 0.3685 & 0.3285 & 0.2912 & 0.2544 & 0.2167 & 0.1795 & 0.1422 & 0.1049 & 0.0677 \\
\hline \multicolumn{8}{|c|}{ COD $=\mathbf{0 . 9 9 2 5 2 6}$} \\
\hline
\end{tabular}




$$
\hat{a}=0.4030 ; \quad \hat{b}=-0.3726 ; \hat{P}_{1}=a+b . L_{1} ; \quad \hat{P}_{1}=0.4030-0.3726 .\left(L_{1}\right)
$$

Table 3

\begin{tabular}{|l|l|l|l|l|l|l|l|l|l|}
\hline \multicolumn{2}{|c|}{ Fixed parameter $\mathrm{p}=0.8, \mathrm{~L}_{2}=0.7, \mathrm{p}_{\mathrm{A}}=02, \mathrm{C}_{1}=0.7$} \\
\hline $\mathrm{L}_{1}$ & 0.1 & 0.2 & 0.3 & 0.4 & 0.5 & 0.6 & 0.7 & 0.8 & 0.9 \\
\hline $\mathrm{P}_{1}$ & 0.5579 & 0.5049 & 0.4499 & 0.3929 & 0.3337 & 0.2722 & 0.2082 & 0.1416 & 0.0723 \\
\hline$\hat{P}_{1}$ & 0.5684 & 0.5078 & 0.4472 & 0.3866 & 0.3261 & 0.2653 & 0.2047 & 0.1441 & 0.0835 \\
\hline & & & \multicolumn{7}{|c|}{ COD=0.998215 } \\
\hline
\end{tabular}

$$
\hat{a}=0.6289 ; \quad \hat{b}=-0.6060 ; \hat{P}_{1}=a+b . L_{1} ; \quad \hat{P}_{1}=0.6289-0.6060 .\left(L_{1}\right)
$$

\section{CONFIDENCE OF INTERVALS (COI)}

The 100(1- $\alpha$ ) percent confidence interval for $\mathrm{a}$ and $\mathrm{b}$ are $\hat{a} \pm\left\{t_{(n-2)} \frac{\alpha}{2}\right\} \cdot s\left[\sqrt{\frac{1}{n}+\frac{\overline{L_{1}}}{\sum_{i=1}^{n}\left(L_{1 i}-\overline{L_{1}}\right)^{2}}}\right] \ldots$

Where $\overline{L_{1}}=\frac{1}{n} \sum_{i=0}^{n} L_{1 i}$. The $\overline{L_{1}}=4.5$ from table $(1,2$ and 3$)$

\begin{tabular}{|c|c|c|c|}
\hline $\begin{array}{c}\text { Fixed } \\
\text { parameter }\end{array}$ & $\begin{array}{c}\text { Constant } \\
\text { (a) }\end{array}$ & $\begin{array}{l}\text { Constant } \\
\text { (b) }\end{array}$ & Confidence Intervel \\
\hline $\begin{array}{c}\mathrm{p}=0.4, \mathrm{~L}_{2}= \\
0.3, \mathrm{p}_{\mathrm{A}}=0.2, \\
\mathrm{C}_{1}=0.3\end{array}$ & $\begin{array}{c}\hat{a}=0.169 \\
0\end{array}$ & $\begin{array}{c}\hat{b}=- \\
0.1622\end{array}$ & $\begin{array}{c}\text { For: }(\mathrm{a}=0.16381, \\
\mathrm{a}=0.17435) \\
\text { For: }(\mathrm{b}=-0.15800, \mathrm{~b}=- \\
0.16642)\end{array}$ \\
\hline $\begin{array}{c}\mathrm{p}=0.6, \mathrm{~L}_{2}= \\
0.5, \mathrm{p}_{\mathrm{A}}=0.2, \\
\mathrm{C}_{1}=0.5\end{array}$ & $\hat{a}=0.403$ & $\begin{array}{c}\hat{b}=- \\
0.3726\end{array}$ & $\begin{array}{c}\text { For: }(a=0.38117, \\
\quad a=0.42489) \\
\text { For: }(b=-0.35522, \\
b=-0.39003)\end{array}$ \\
\hline $\begin{array}{c}\mathrm{p}=0.8, \mathrm{~L}_{2}= \\
0.7, \mathrm{p}_{\mathrm{A}}=0.2,\end{array}$ & $\hat{a}=0.628$ & $\hat{b}=-$ & $\begin{array}{c}\text { For: }(a=0.61121, \\
a=0.64673)\end{array}$ \\
\hline
\end{tabular}

\section{Table: 4 Confidence interval for $a$ and $b$}

$$
\hat{b} \pm\left\{t_{(n-2)}, \frac{\alpha}{2}\right\} \cdot s\left[\sqrt{\sum_{i=1}^{n}\left(L_{1 i}-\overline{L_{1}}\right)^{2}}\right]
$$

Where $\mathrm{s}=\sqrt{\frac{\sum\left(P_{i}-\hat{P}_{i}\right)^{2}}{n-2}}$ and $t_{(n-2)} \frac{\alpha}{2}$ is obtained from standard table. take $\alpha=0.05, \mathrm{n}=9$ then $\mathrm{t}_{7}, 0.025=2.365$

\begin{tabular}{|c|c|c|c|}
\hline $\mathrm{C}_{1}=0.7$ & 9 & 0.6060 & $\begin{array}{c}\text { For: }(\mathrm{b}=-0.59188, \\
\mathrm{b}=-0.62018)\end{array}$ \\
\hline $\begin{array}{c}\text { Average } \\
\text { Estimates }\end{array}$ & $\bar{a}=0.40$ & $\bar{b}=-0.3$ & $\begin{array}{c}\hat{P_{1}}=\bar{a}+\bar{b}\left(L_{1}\right) \\
\hat{P_{1}}=0.400915-0\end{array}$ \\
& & & \\
\hline
\end{tabular}

\section{AVERAGE RELATIONSHIP}

we define $\hat{P}=\bar{a}+\bar{b}\left(L_{1}\right)$ in table 4 where $\bar{a}, \bar{b}$ are average estimate obtain through all tables. We found that $\hat{P}_{1}=0.400915-0.381292 .\left(L_{1}\right)$ 


\section{CONCLUSION}

In a contribution Shukla,Tiwari and Thakur [24] have suggested a mathematical relation depending on many model parameters. But there is no direct relation exist between $\mathrm{P}_{1}$ and $\mathrm{L}_{1}$. Using the model relation and least square method together we have obtained the simplified relation as $\hat{P}_{1}=0.400915-0.381292 .\left(L_{1}\right)$.

The coefficient of determination is nearly equal to 1 , showing strength of the fitting of straight line. This suggested linear relationship is just like a first hand preliminary rule. The beauty of expression is that it is independent of model parameters.

\section{REFERENCES}

[1]. Medhi, J. (1991): Stochastic models in queuing theory, Academic Press Professional, Inc., San Diego, CA.

[2]. Medhi, J. (1992): Stochastic Processes, Ed.4, Wiley Eastern Limited (Fourth reprint), New Delhi.

[3]. Chen, D.X. and Mark, J.W. (1993): A fast packet switch shared concentration and output queuing, IEEE Transactions on Networking, vol. 1, no. 1, pp. 142-151.

[4]. Hambali, H. and Ramani, A. K., (2002): A performance study of at multicast switch with different traffics, Malaysian Journal of Computer Science. Vol. 15, Issue No. 02 , Pp. 34-42.

[5]. Naldi, M. (2002): Internet access traffic sharing in a multiuser environment, Computer Networks. Vol. 38, pp. 809824.

[6]. Newby, M. and Dagg, R. (2002): Optical inspection and maintenance for stochastically deteriorating systems: average cost criteria, Jour. Ind. Statistical Associations. Vol. 40, Issue No. 02, pp. 169-198.

[7]. Francini, A. and Chiussi, F.M. (2002): Providing QoS guarantees to unicast and multicast flows in multistage packet switches, IEEE Selected Areas in Communications, vol. 20, no. 8, pp. 1589-1601.

[8]. Dorea, C.C.Y., Cruz and Rojas, J. A. (2004): Approximation results for non-homogeneous Markov chains and some applications, Sankhya. Vol. 66, Issue No. 02, pp. 243-252.

[9]. Paxson, Vern, (2004): Experiences with internet traffic measurement and analysis, ICSI Center for Internet Research International Computer Science Institute and Lawrence Berkeley National Laboratory.

[10]. Yeian, C. and Lygeres, J. (2005): Stabilization of class of stochastic differential equations with Markovian switching, System and Control Letters. Issue 09, pp. 819833.
[11]. Shukla, D., Gadewar, S. and Pathak, R.K. (2007 a): A stochastic model for space division switches in computer networks, International Journal of Applied Mathematics and Computation, Elsevier Journals, Vol. 184, Issue No. 02, pp235-269.

[12]. Shukla, D. and Thakur, Sanjay, (2007 b) Crime based user analysis in internet traffic sharing under cyber crime, Proceedings of National Conference on Network Security and Management (NCSM-07), pp. 155-165, 2007.

[13]. Shukla, D., Virendra Tiwari, M. Tiwari and Sanjay Thakur [2007 c]: Rest State analysis of Internet traffic distribution in multi-operator environment published in the Journal of management Information Technology (JMIT-09), Vol. 1, pp. 72-82

[14]. Agarwal, Rinkle and Kaur, Lakhwinder (2008): On reliability analysis of fault-tolerant multistage interconnection networks, International Journal of Computer Science and Security (IJCSS) Vol. 02, Issue No. 04, pp. 1-8.

[15].Shukla, D., Tiwari, Virendra, Thakur, S. and Deshmukh, A. (2009 a):Share loss analysis of internet traffic distribution in computer networks, International Journal of Computer Science and Security (IJCSS), Malaysia, Vol. 03, issue No. 05, pp. 414-426.

[16]. Shukla, D., Tiwari, Virendra, Thakur, S. and Tiwari, M. (2009 b) :A comparison of methods for internet traffic sharing in computer network, International Journal of Advanced Networking and Applications (IJANA).Vol. 01, Issue No.03, pp.164-169.

[17]. Shukla, D., Tiwari, V. and Kareem, Abdul, (2009 c) All comparison analysis in internet traffic sharing using markov chain model in computer networks, Georgian Electronic Scientific Journal: Computer Science and Telecommunications. Vol. 06, Issue No. 23, pp. 108-115.

[18]. Shukla, D, Tiwari, M., Thakur, Sanjay and Tiwari, Virendra [2009 d]: Rest State Analysis in Internet Traffic Distribution in Multi-operator Environment, (GNIM's) Research Journal of Management and Information Technology, Vol. 1, No. 1, pp. 72-82.

[19].Shukla, D. and Thakur, Sanjay [2009 e]: Modeling of Behavior of Cyber Criminals When Two Internet Operators in Markets, Accepted for publication in ACCST Research Journal, Vol. VIII, No. 3, July, (2009).

[20]. Shukla, D., Jain Saurabh, Singhai Rahul and Agarwal R.K. [2009 f]: A Markov chain model for the analysis of round robin scheduling scheme, International Journal of Advanced Networking and Applications (IJANA), vol. 01, no. 01, pp. 01-07.

[21]. Shukla, D., Thakur S. and Deshmukh Arvind [2009 g]: State probability analysis of Internet traffic sharing in 
computer network, International Journal of Advanced Networking and Applications (IJANA), vol. 1, issue 1, pp. 90-95.

[22]. Shukla, D., Tiwari, Virendra, and Thakur, S. (2010 a): Effects of disconnectivity analysis for congestion control in internet traffic sharing, National Conference on Research and Development Trends in ICT (RDTICT2010), Lucknow University, Lucknow.

[23].Shukla, D., Gangele, Sharad and Verma, Kapil, (2010 b): Internet traffic sharing under multi-market situations, Published in Proceedings of 2nd National conference on Software Engineering and Information Security, Acropolis Institute of Technology and Research, Indore, MP, (Dec. 23-24,2010), pp 49-55.

[24].Shukla, D., and Thakur, S. (2010 c): Stochastic Analysis of Marketing Strategies in internet Traffic, INTERSTAT (June 2010).

[25].Shukla, D., Tiwari, V., and Thakur, S., (2010 d): Cyber Crime Analysis for Multi-dimensional Effect in Computer Network, Journal of Global Research in Computer Science(JGRCS), Vol. 01, Issue 04, pp.31-36.

[26].Shukla, D., Tiwari V. and Thakur S. [2010 e]: User behavior Based Probability Analysis of Internet Traffic Distribution in Two market in Computer Networks, Kalpagam Journal of Cambridge Studies (KJCS)

[27].Shukla, D., Tiwari V. and Thakur S. [2010 f]: Performance Analysis for Two Call Attempt of rest State Based Traffic Network, International Journal of Advanced Networking and Application (IJANA)

[28].Shukla, D. and Thakur, Sanjay [2010]: Index based Internet traffic sharing analysis of users by a Markov chain probability model. , Karpagam Journal of Computer Science, vol. 4, no. 3, pp. 1539-1545.

[29]. Shukla, D., Tiwari, V., Thakur, S. and Deshmukh, A.K. [2010 a]: Two call based analysis of internet traffic sharing, International Journal of Computer and Engineering (IJCE), Vol. 1, No. 1, pp. 14-24.

[30].Shukla, D. and Singhai, Rahul [2010 b]: Traffic analysis of message flow in three cross-bar architecture in space division switches, Karpagam Journal of Computer Science, vol. 4, no. 3, pp. 1560-1569.

[31]. Shukla, D., Thakur, Sanjay and Tiwari, Virendra [2010 c]: Stochastic modeling of Internet traffic management, International Journal of the Computer the Internet and Management, Vol. 18, no. 2 pp. 48-54.

[32]. Shukla, D., Tiwari, Virendra and Thakur, Sanjay [2010 d]: Cyber crime analysis for multi-dimensional effect in computer network, Journal of Global Research in Computer Science, Vol.1, no. 4. pp. 14-21.
[33]. Shukla, D. and Thakur, Sanjay [2010 e ]: Iso-share Analysis of Internet Traffic Sharing in Presence of Favoured Disconnectivity, GESJ: Computer Science and Telecommunications, 4(27), pp. 16-22.

[34]. Shukla, D., Gangele, Sharad, Verma, Kapil and Singh, Pankaja (2011 a): Elasticity of Internet Traffic Distribution Computer Network in two Market Environment, Journal of Global research in Computer Science (JGRCS) Vol.2, No. 6, pp.6-12.

[35]. Shukla, D., Gangele, Sharad, Verma, Kapil and Singh, Pankaja (2011 b): Elasticities and Index Analysis of Usual Internet Browser share Problem, International Journal of Advanced Research in Computer Science (IJARCS),Vol. 02, No. 04, pp.473-478.

[36].Shukla, D., Gangele, Sharad, Verma, Kapil and Thakur, Sanjay, (2011 c): A Study on Index Based Analysis of Users of Internet Traffic Sharing in Computer Networking, World Applied Programming (WAP), Vol 01, No. 04, pp. 278-287.

[37]. Shukla, D., Tiwari, Virendra and Thakur, Sanjay [2011] Analysis of Internet Traffic Distribution for User Behavior Based Probability in Two Market Environment, International Journal of Computer Application (IJCA), Vol. 30, Issue No. 08. pp. 44-51.

[38]. Shukla, D., Gangele, Sharad, Singhai, Rahul and Verma, Kapil, (2011 d): Elasticity Analysis of Web Browsing Behavior of Users, International Journal of Advanced Networking and Applications (IJANA), Vol. 03, No. 03, pp.1162-1168.

[39]. Shukla, D., Verma, Kapil and Gangele, Sharad, (2011 e): Re-Attempt Connectivity to Internet Analysis of User by Markov Chain Model, International Journal of Research in Computer Application and Management (IJRCM) Vol. 01, Issue No. 09, pp. 94-99.

[40]. Shukla, D., Gangele, Sharad, Verma, Kapil and Trivedi, Manish, (2011 f): Elasticity variation under Rest State Environment In case of Internet Traffic Sharing in Computer Network, International Journal of Computer Technology and Application (IJCTA) Vol. 02, Issue No. 06, pp. 2052-2060.

[41]. Shukla, D., Gangele, Sharad, Verma, Kapil and Trivedi, Manish, [2011]: Two-Call Based Cyber Crime Elasticity Analysis of Internet Traffic Sharing In Computer Network, International Journal of Computer Application (IJCA) Vol.02, Issue 01, pp.27-38.

[42]. Shukla, D., Singhai, Rahul [2011]: Analysis of User Web Browsing Using Markov chain Model, International Journal of Advanced Networking and Application (IJANA), Vol. 02, Issue No. 05, pp. 824-830. 
[43]. Shukla, D., Verma, Kapil and Gangele, Sharad, [2012]: Iso-Failure in Web Browsing using Markov Chain Model and Curve Fitting Analysis, International Journal of Modern Engineering Research(IJMER), Vol. 02, Issue 02, pp. 512-517.

[44]. Shukla, D., Verma, Kapil and Gangele, Sharad, [2012]: Least Square Curve Fitting in Internet Access Traffic Sharing in Two Operator Environment, International Journal of Computer Application (IJCA), Vol.43(12), pp. 26-32.

[45]. Shukla, D., Verma, Kapil and Gangele, Sharad, [2012]: Least Square Curve Fitting Applications under Rest State Environment in Internet Traffic Sharing in
Computer Network, International Journal of Computer Science and Telecommunications (IJCST), Vol. 03, Issue 05 .

[46]. Shukla, D., Verma, Kapil and Gangele, Sharad, [2012]: Curve Fitting Approximation in Internet Traffic Distribution in Computer Network in Two Market Environment, International journal of Computer Science and Information Security (IJCSIS), Vol. 10, Issue 05, pp. 71-78.

[47]. Shukla, D., Verma, Kapil, Dubey, Jayant and Gangele, Sharad, [2012]: Cyber crime Based Curve Fitting Analysis in Internet Traffic Sharing in Computer Network, International Journal of Computer Application (IJCA), Vol.46(22), pp. 41-51. 